\title{
A transmissão da psicanálise, a política do psicanalista e sua presença nos dispositivos universitários e de atenção à saúde mental
}

Luis Achilles Rodriges Furtado e Camilla Araújo Lopes Vieira

\begin{abstract}
Resumo
O presente artigo busca discutir as questões em torno do ensino e da transmissão da psicanálise por meio do trabalho realizado em uma cidade do interior da região Nordeste brasileira e os efeitos da presença do psicanalista na universidade e na pólis, sustentando a lógica da falta-a-ser como operadora de seu ato. Nesse sentido, busca-se abordar o trabalho nos dispositivos universitários e de saúde mental como experiências a serem discutidas a partir dos problemas apresentados à própria psicanálise em um mundo totalitário e segregatório.
\end{abstract}

\section{Palavras-chave:}

Psicanálise; Políticas públicas; Saúde mental; Supervisão.

\section{The transmission of psychoanalysis, the psychoanalyst's policy and their presence in university devices and mental health care}

\begin{abstract}
The present work seeks to discuss the questions surrounding the teaching and transmission of psychoanalysis through the work carried out in a country town of the Brazilian Northeast region and the effects of the psychoanalyst's presence in the university and in the polis supporting the logic of lack-to-be as operator of your act. In this sense, it is sought to approach the work in university and mental health devices as experiences to be discussed from the problems posed to psychoanalysis itself in a totalitarian and segregatory world.
\end{abstract}

\section{Keywords:}

Psychoanalysis; Public policy; Mental health; Supervision. 


\title{
La transmisión del psicoanálisis, la política del psicoanalista y su presencia en los dispositivos universitarios y de atención a la salud mental
}

\begin{abstract}
Resumen
El presente trabajo busca discutir las cuestiones en torno a la enseñanza y la transmisión del psicoanálisis a través del trabajo realizado en una ciudad de la Región Nordeste brasileña y los efectos de la presencia del psicoanalista en la universidad y en la polis sosteniendo la lógica de la falta-en-ser como operadora de su acto. En este sentido, se busca abordar el trabajo en los dispositivos universitarios y de salud mental como experiencias para discutir a partir de los problemas planteados al propio psicoanálisis en un mundo totalitario y segregativo.
\end{abstract}

\section{Palabras clave:}

Psicoanálisis; Políticas públicas; Salud mental; Supervisión.

\section{La transmission de la psychanalyse, la politique du psycha- nalyste et sa présence dans les dispositifs universitaires et de soins de santé mentale}

\begin{abstract}
Résumé
Ce présent travail vise à discuter les questions concernant l'enseignement et la transmission de la psychanalyse à travers le travail effectué dans une ville de la région nord-est brésilienne et les effets de la présence du psychanalyste dans l'université et dans la polis, soutenant la logique du manque-à-être comme opérateur de son acte. En ce sens, on cherche à aborder le travail dans les dispositifs universitaires et de santé mentale comme des expériences à discuter à partir des problèmes posés à la psychanalyse elle-même dans un monde totalitaire et de ségrégation.
\end{abstract}

\section{Mots-clés :}

Psychanalyse ; Politiques publiques ; Santé mentale ; Contrôle.

O desejo que mobilizou a escrita deste texto está relacionado com as diversas dificuldades que enfrentamos nos últimos 10 anos no que se refere ao trabalho e, por que não dizer, à introdução da psicanálise no sertão do Ceará. Em um cenário no qual a presença de colegas psicanalistas era praticamente insignificante, a referência à Escola de Psicanálise foi não só um ponto de partida, mas fundamental para a manutenção de um trabalho. Nos últimos meses, foi a partir do convite para ocupar a função de supervisor clínico-institucional da rede de saúde mental da cidade de 
Sobral que alguns elementos começaram a se apresentar para nossa reflexão. Perguntamo-nos sobre a relação que essa demanda poderia ter não com a universidade, mas com nossa própria relação com a Escola, a clínica, o ensino e a transmissão.

Qualquer professor universitário brasileiro sabe que é uma arte conseguir não ser suprimido pelo rolo compressor da burocracia, do poder, da economia dos créditos implicada na fabricação dos ilustres que não têm compromisso com o saber fazendo barreira a ele (Lacan, 1970/2003). A lógica capitalista do funcionamento universitário, das citações, do currículo Lattes, das funções administrativas, dos benefícios financeiros e materiais para as pesquisas obedece a uma política que tem como efeito a produção de sujeitos adoecidos e/ou presunçosos.

Como distinguir se os efeitos de trabalho de alguém que está inserido na universidade decorrem de uma conjuntura político-econômica local ou dos próprios efeitos de seu ato como psicanalista?

Lacan (1975, inédito), em uma de suas conferências nos Estados Unidos, questiona a existência do psicanalista. Ou seja, aquele que, depois da descoberta freudiana, dedica-se ao inconsciente em seu ofício pode confundir sua função com seu ser? É possível "ser psicanalista"? Sabemos que o que se espera de um psicanalista é uma psicanálise, mas isso é da ordem do ser?

Curioso é lembrar que, em seu texto "A direção do tratamento e os princípios de seu poder" (1958/1998), Lacan afirma que aquilo no qual somos menos livres, em contraponto à estratégia e à tática, é no que se refere à nossa política, a falta-a-ser. Tal como com o sujeito, na hora que tentamos tocar, imaginarizar, o ser do analista, ele se esvanece. Entendida como um campo que implica a "administração da relação entre os homens", ou seja, o campo do laço social, a política aborda o exercício de um poder impossível sobre o gozo. Uma diferença surge, justamente, quando se estabelece um laço no qual seu agente sustenta a falta de gozo que muitos tentam escamotear.

Assim, seja em uma universidade, seja em uma escola de psicanálise ou em um dispositivo público de saúde mental (por exemplo), a presença de um psicanalista não se verifica pela dimensão imaginária do "ser psicanalista", mas por seu ato, verificado no só-depois. A implicação desse ato tem relação com uma rede de significantes da qual a função do sujeito se destaca, barrando o gozo que ameaça os indivíduos que o procuram na espera de que seu trabalho possa contribuir com sua realidade subjetiva e, por que não dizer, coletiva e política.

Enfim, além de muita paciência, solidão e criatividade, a introdução da psicanálise em um lugar onde não há tradição desse trabalho implica uma aposta renovada e na qual a experiência de Escola adquire papel fundamental.

Se entendemos que transmissão é algo que se depura da experiência do psicanalista com seus analisantes e com sua própria análise, o ensino da psicanálise fica diretamente marcado pelos efeitos dessa transmissão. Sua relação com o real, e 
não apenas com a rede de significantes que compõem a teoria psicanalítica, implica a presença de um modo específico de laço que faça contraponto à lógica do Um, da completude do saber e das respostas metodologicamente articuladas e eficazes.

Pode-se ter muito conhecimento, mas não saber absolutamente nada do que fazer com ele. A coisa fica mais difícil ainda quando não só não se sabe o que fazer com o conhecimento, mas não se tem ideia do que fazer com o não saber!!!

Uma vez que os efeitos da própria análise se constatam, o exercício da função de ensinante não necessariamente constitui-se em sinônimo de pacto com a burocracia. Surge aí algo que é da ordem da relação com o não saber que se passa, transmite-se pela via não dos enunciados, mas pela enunciação, pelo ato, e a própria burocracia fica, assim, implodida.

Lacan (1970/2003, p. 303), em sua Alocução sobre o ensino, mostra-se perplexo com a confusão que se apresentava no que se refere à noção de ensino. Ele critica o fato de se tomar por evidente a afirmação de que o ensino seria a transmissão de um saber. Ele nos diz:

Dou a isso uma reflexão, balística, entendam-na, ao me espantar de que a todo instante tenha parecido evidente que o ensino era a transmissão de um saber, tomando-se por horizonte o pêndulo que vai entre aquele que ensina [enseignant/ensinante] e o ensinado [enseigné]: a relação entre eles (...) é o barco que convém, ao encontrar, na grande feira de nossa época, seu impulso, não mais disparatada do que a relação médico-paciente, por exemplo. (Lacan, 1970/2003, p. 303)

Aqui, a palavra "bateau", traduzida como "barco", tem o sentido de "conto da carochinha", "conversa fiada", "barca furada”. Ou seja, Lacan critica a confusão ocorrida entre os psicanalistas de sua Escola quando apresentam a discussão sobre o ensino nos termos da chamada relação "ensinante-ensinado", que em nossa língua é popular como "relação professor-aluno". Hoje, podemos verificar nas discussões em torno da humanização em saúde, no campo da pedagogia e até no campo da educação permanente em saúde, o atrelamento da valorização da qualidade relacional nos pares médico-paciente, trabalhador-usuário e professor-aluno. Contudo, a discussão beira a hipocrisia por estabelecer uma retórica que prega o papel ativo do indivíduo, quando todo o sistema de trabalho, sistema pedagógico e sistema de serviços está montado para responder a uma demanda de produtividade e eficácia. Sem a consideração do que está em jogo no que tange ao desejo e à falta, tal destaque do valor dessas relações revela-se como algo que

1 No original: "c'est le bateau qu'il y faut...". 
anda de mãos dadas com a lógica capitalista contemporânea. Basta notarmos a proliferação dos messiânicos coachings espalhados pelo Brasil. Nesse sentido, é impressionante a atualidade dessa fala improvisada de Lacan há 44 anos.

Confundir a dimensão da transferência - e do desejo, portanto - com teorizações moralizantes que destacam a "qualidade" da relação entre ensinante-ensinado ou médico-paciente implica o salto imediato para o campo do imaginário, no qual reinam a popularidade, a completude, o mercado de favores e suas íntimas hierarquias. Uma verdadeira barca furada!

Ao lermos esse texto de Lacan, precisamos observar o efeito de significação que o par "enseignant-enseigné" carrega na língua francesa. Trata-se de um par de opostos que implica a voz ativa e a passiva, que podem se perder na tradução por "professor-aluno". O par "ensinante-ensinado" implica a oposição clássica entre um sujeito e o objeto desse ensino. Contudo, professor, como aquele que profere, só se constitui no só-depois e na relação com um saber que se "transmite" a partir de seu ato que é determinado por sua condição de sujeito e pela condição de sujeito daqueles que o escutam. É ao falar que algo vai além do que chamamos conhecimento, que tem a ver com outra ordem e que diz respeito à relação de cada um com suas próprias questões, ou seja, com seu não saber.

É nesse contexto que a presença de um psicanalista pode ser convocada a partir de um ensino. Quantos psicanalistas conhecemos que trabalham em nosso gravemente ameaçado Sistema Único de Saúde (SUS) e dão testemunho disso? Como sustentar a solidão de seu ato no contexto disciplinar das diversas práticas sem a referência à Escola à qual dedica sua formação?

É nessa perspectiva que, após 10 anos de trabalho no sertão, sustentamos que é o trabalho em direção à Escola que permite sua presença nos diversos cenários. Nesse sentido, não é o psicanalista que está na Escola, mas é a Escola que se presentifica no psicanalista por meio de seus efeitos e seus diversos sotaques.

Contudo, da mesma forma que é preciso um tempo para o atravessamento na análise de cada um, há também um tempo necessário para que a pólis possa receber a novidade do ato psicanalítico. Lembremos as dificuldades enfrentadas por Freud e os anos necessários para se esgotar a primeira edição de A interpretação dos sonhos. Se considerarmos as distorções nos conceitos freudianos ocorridos na história, poderemos nos perguntar se não foi a própria clínica de Freud e sua relação com o desejo e com o inconsciente que imprimiram algo que foi além do "ensinado" em suas obras.

Assim, o tempo que a pólis pode levar no que se refere a um trabalho de transmissão da psicanálise implica o tempo das análises que começam a ser conduzidas onde antes praticamente não havia. Esse tempo implica os efeitos analíticos das supervisões que porventura podem até acontecer e se iniciar no âmbito acadêmico. Outras atividades também imprimem suas consequências, como as apre- 
sentações clínicas de pacientes, a construção de casos, o ensino, a arte etc. Destacamos, portanto, não a natureza da atividade ou do trabalho realizado - coisas que podem ser facilmente contabilizadas -, mas o enlace que cada psicanalista tem com esse trabalho, o que não necessariamente precisa aparecer na forma de apresentação de relato de casos, por exemplo, apesar de ter relações diretas com a clínica por ser dela depurada, como nos lembra Antonio Quinet (2009).

Se, de um lado, a transmissão relaciona-se com o ato, com a psicanálise em intensão, o ensino relaciona-se com a extensão. Uma vez que admitimos que um ensino só se verifica depois, por seus efeitos, a função do sujeito é constatada como determinante. O ensinante, para a psicanálise, é o sujeito, o que fala no divã e o que profere em seu ensino. Daí Lacan afirmar que tudo o que aprendeu foi com seus analisantes e que fazia seu seminário a partir dessa posição. Desse modo, ensino e transmissão podem ser enlaçados sem que a lógica da manutenção do Um do saber se instaure e sem confusão entre essas dimensões.

Enfim, sustentar a presença do psicanalista nos dispositivos de atenção à saúde mental ou no contexto universitário não se distancia do que Lacan chamou de sua política na direção do tratamento. Longe de seu ato configurar uma psicanálise de grupo ou das instituições, ele aponta sempre para o sujeito de um discurso e para sua relação com a falta. Seu efeito é de elaboração, e, de início, elaboração da demanda. Interrogar o rolo compressor da demanda das instituições universitárias e de saúde implica o rompimento com o pacto de silêncio e de gozo que assola diversos colegas no país. Aqui, vemos um dos grandes problemas para a psicanálise nos dias atuais.

Entendemos que a presença da psicanálise nos dispositivos de atenção à saúde mental - entendidos como dispositivos transversais que não pertencem unicamente ao campo da saúde - é necessária e justificada. Justifica-se pelos efeitos do trabalho no plano coletivo e individual traduzidos pela presentificação de uma ética que leva em conta o desejo, a função da fala e o campo da linguagem. A psicanálise, ali, é necessária por permitir uma clínica estrutural que leva em conta a relação do sujeito com o Outro, com o gozo, com a falta e sua posição na fantasia. Tal clínica distancia-se dos equívocos da clínica pautada pela classificação da demanda e sua medicalização ou terapeutização.

Percebemos incontáveis experiências de psicanalistas que trabalham nas universidades e que passam a operar também nas redes de atenção à saúde mental ou instituições de saúde nos diversos níveis de atenção. A premissa de que o SUS deve estar articulado com o ensino para a qualificação dos trabalhadores e da gestão não é suficiente para compreender a presença, mesmo que ameaçada, da psicanálise nesse campo. Trata-se, antes, de um manejo que surge da experiência em outro lugar. 
Enfim, é porque pode e pôde ocupar a condição de sujeito que a virada em um discurso pode acontecer em algumas circunstâncias. É por isso que, mesmo na condição de ensinante, podem-se produzir efeitos analíticos, e é daí que podemos concluir que o ensinado, tal como o trabalhador da saúde mental, pode ser convocado em sua condição de sujeito, abrir mão do gozo e, enfim, elaborar algo em torno do não saber.

\section{Referências bibliográficas}

Lacan, J. (1958/1998). A direção do tratamento e os princípios de seu poder. In J. Lacan. Escritos (Vera Ribeiro, Trad.) (pp. 591-652). Rio de Janeiro: Jorge Zahar. Lacan, J. (1970/2003). Allocution prononcée pour la clôture du congrès de l'École freudienne de Paris le 19 avril 1970, par son directeur. Scilicet, 4ำ trimestre, (2-3), 391-399. Obtido em 10 de outubro de 2016. Recuperado de http://aejcpp. free.fr/lacan/1970-04-19d.htm

Lacan, J. (1975). Conferências nos Estados Unidos. Inédito.

Quinet, A. (2009). A estranheza da psicanálise. Rio de Janeiro: Jorge Zahar.

Recebido: 14/04/2018

Aprovado: 21/05/2018 